\title{
TRABALHOS EM PEDRA E OFÍCIO DA CANTARIA NA ZONA DA MATA MINEIRA
}

\author{
Ricardo De Cristofaro \\ Professor, UFJF, Instituto de Artes e Design \\ cristofa@terra.com.br
}

Resumo: Trabalhos em pedra realizados na Zona da Mata Mineira com ênfase na cidade de Juiz de Fora seus diversos períodos de formação. Apresenta uma perspectiva histórica capaz de propiciar conhecimento de determinadas mudanças e/ou características que aparecem em obras realizadas com diferentes rochas e técnicas, em especial relacionadas ao ofício da cantaria.

Palavras Chave: cantaria, Zona da Mata Mineira, Juiz de Fora

Abstract: WORKS IN STONE AND TRADITION OF CANTARIA IN THE ZONA DA MATA MINEIRA. Stone work in the Zona da Mata Mineira emphasizing the city of Juiz de Fora its various training periods. It offers a historical perspective can provide knowledge of certain changes and / or characteristics that appear in the works with different rocks and techniques, especially related to the craft of stone masonry.

Keywords: stone masonry, Zona da Mata Mineira, Juiz de Fora

\section{O CAMINHO NOVO E A ZONA DA MATA}

A utilização de pedras e técnicas de cantaria em Minas Gerais acompanhou as etapas de ocupação do território no século XVIII, ocorrendo à medida que surgiam arraiais e vilas próximas aos locais de extração de ouro, bem como ao longo dos caminhos que levavam aos núcleos mineradores.

Com o enriquecimento das vilas e o crescente aumento populacional dos principais núcleos urbanos, houve a necessidade e a vontade de se promover tanto a melhoria das condições de urbanização quanto a construção de novas residências, unidades administrativas e religiosas. Nesse processo, pedras foram amplamente adotadas junto com os métodos de construção com barro cru (adobe) e taipa, para a realização de cunhais, cercaduras, umbrais, soleiras e escadas. Isso ocorreu simultaneamente com as construções dos primeiros edifícios de pedra. Essas transformações exigiram a presença de mestres de cantaria vindos de Portugal e de outros centros, além do treinamento de aprendizes locais.

Trabalhos em pedra começaram a ser realizados na região da Zona da Mata Mineira no início do século XVIII, a partir da ocupação de sesmarias concedidas pela Coroa Portuguesa ao longo do Caminho Novo. Nos terrenos que pertenciam a essas propriedades, é possível identificar a utilização de rochas para a produção de marcos de propriedade, a construção de muros, escadas e, principalmente, de alicerces de edificações (Figura 1).

Às margens do Caminho Novo, foram surgindo postos de registro e fiscalização de mercadorias, além de roças, hospedarias, armazéns e ranchos para tropas, situação que perdurou durante todo período de extração de ouro e pedras preciosas no interior da Província de Minas Gerais.

No início do século XIX, quando o ouro já se encontrava escasso e de difícil extração, arraiais vão

doi: $10.18285 /$ geonomos.v24i2.878 sendo formados no interior de Minas, em grande parte, em função da dispersão dos povoados mineradores e de uma reorientação da atividade econômica na colônia. É a situação verificada no distrito de Santo Antônio do Juiz de Fora, elevado à condição de Vila em 1850, quando a maior parte de seu núcleo urbano já se localizava na margem direita do Rio Paraibuna (BASTOS, 1993).

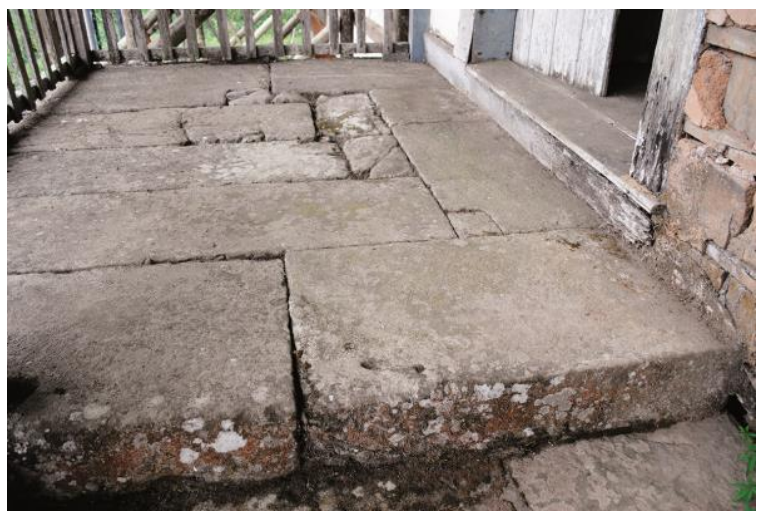

Figura 1. Trabalhos de cantaria na escada e varanda da sede da Fazenda Ribeirão das Rosas no município de Juiz de Fora, MG, 1751. Fonte: acervo fotográfico Ricardo De Cristofaro.

$\mathrm{Na}$ Vila de Santo Antônio foram erguidas residências, estabelecimentos comerciais e administrativos, com métodos típicos da arquitetura colonial mineira. Essas obras eram, em sua maioria, feitas com fundações em pedra e barro, paredes externas e internas de adobe e taipa com acabamento caiado. Muito comum também foi a existência das chamadas "cabanas" ou "casas de capim", com chão de terra batida.

Construções mais elaboradas eram muito raras, restringindo-se a residências particulares de famílias abastadas ou a obras financiadas por elas. Nesses casos, os recursos financeiros determinaram o uso de técnicas e materiais específicos. Isso pode ser percebido em um documento de 1847 que trata dos planos de edificação da terceira capela dedicada a Santo Antônio: “...teria o corpo cem palmos de comprimento, todo de alicerçado de pedras de seis 
palmos de altura, sendo parte das paredes de adobe e parte de pau a pique" (ESTEVES; VIDAL, 2008, p.53).

Nas primeiras décadas de existência do arraial e, posteriormente, da vila, percebe-se, por documentos e antigas edificações, que a utilização de pedras era bastante limitada. Isso se devia à dificuldade e à demora na realização dos trabalhos em pedra e, principalmente, à inexistência de trabalhadores especializados na região.

Em documento encaminhado à Câmara dos Vereadores em 1857, José Antônio da Silva Pinto, conhecido como Barão de Bertioga, reconhece ter construído uma "coluna hidráulica", destinada a uso público no Largo do Senhor dos Passos, em material inferior ao que gostaria de ter usado. Sua primeira intenção era construir um "Chafariz de Cantaria", mas não conseguiu devido a "dificuldades de conseguir um operário hábil que se encarregasse de executar a obra com perfeição" (ESTEVES; VIDAL, 2008, p.57).

As obras em pedra desse período eram bastante simples, limitando-se a alicerces, soleiras, escadas externas, muros, sepulturas, além de cochos e pedras de moinhos d'agua na área rural. Ressalta-se a especificidade das rochas utilizadas na região, notadamente gnaisses e granitos, que afloram em abundância e que são rochas duras quando comparadas aos quartzitos, xistos, e pedras-sabão, frequentemente utilizados nas cidades do "barroco mineiro".

Essa situação - caracterizada pela pouca utilização de pedras em obras e edificações e a ausência de canteiros - iria se modificar com as progressivas transformações econômicas e sociais proporcionadas, principalmente, pela agricultura cafeeira e pela chegada de novos empreendedores, que passaram a investir no desenvolvimento da região e na melhoria da infraestrutura local. Nesse processo, verificamos a criação da "Sociedade Promotora dos Melhoramentos Materiais da Vila" e a formação de uma Câmara de Vereadores empenhada no desenvolvimento regional, bem como a presença de engenheiros preocupados com o escoamento das águas pluviais, o esgotamento de brejos, a higiene pública e com a demarcação, alinhamento e nivelamento das ruas.

\section{A ESTRADA UNIÃO INDÚSTRIA}

O fato mais relevante para o desenvolvimento da cantaria na Zona da Mata e em Juiz de Fora está relacionado à Fundação da Companhia União e Indústria pelo engenheiro Mariano Procópio Ferreira
Laje e à construção da Estrada União e Indústria entre 1856 e 1861.

Projetada para ser uma via rápida e segura para o transporte de mercadorias e passageiros entre a cidade de Petrópolis e Juiz de Fora, a obra, com 144 quilômetros de extensão, foi a primeira estrada macadamizada da América Latina. O percurso tinha 13 estações de muda para as diligências (incluindo as de partida e chegada) e 10 "obras de arte", termo técnico da engenharia da época usado para designar as pontes realizadas com pedra, madeira e ferro (VASQUEZ, 1997).

$\mathrm{Na}$ estrada foram realizados excelentes trabalhos de cantaria nas bases e nos pilares das pontes, nos canais de escoamento de água, nos muros de proteção e contenção, em chafarizes e em marcos de distância. Apesar de muitos desses trabalhos terem sido destruídos em reformas posteriores, ainda hoje podemos observar estruturas que foram abandonadas, reaproveitadas, reformadas e, em alguns casos, preservadas como patrimônio histórico ou removidas para museus. Alguns trabalhos realizados para a Estrada fazem parte do acervo do Museu Rodoviário localizado em Mont' Serrat, município de Comendador Levy Gasparian, RJ.

Consciente da dificuldade de encontrar trabalhadores especializados no Brasil e das restrições impostas ao trabalho escravo, Mariano Procópio contratou engenheiros franceses e alemães para a execução dos projetos e a supervisão das obras, além de um significativo contingente de imigrantes alemães para trabalhar como canteiros e pedreiros, entre outras especialidades. Alguns chegaram com domínio dos ofícios, mas a maior parte foi treinada nas oficinas da companhia (Figura 2) que ficava situada no atual bairro Mariano Procópio em Juiz de Fora (STHELING, 1979).

Apesar da Cia. União Indústria, por força do contrato de concessão, ter sido proibida de utilizar ou empregar escravos nos trabalhos de construção da rodovia, existem muitas evidências da participação de mão de obra escrava, atuando indiretamente pelo sistema de empreitada ou sendo alugada de fazendeiros ao longo da obra.

Temos que considerar que a execução de cantaria em pedra envolve grande esforço físico, além de habilidade, disciplina e da produção de ferramentas específicas. A execução do trabalho é lenta, principalmente quando são utilizadas rochas duras. Nesse sentido, para que uma grande obra avance dentro de um tempo razoável, são necessários vários trabalhadores bem treinados. 


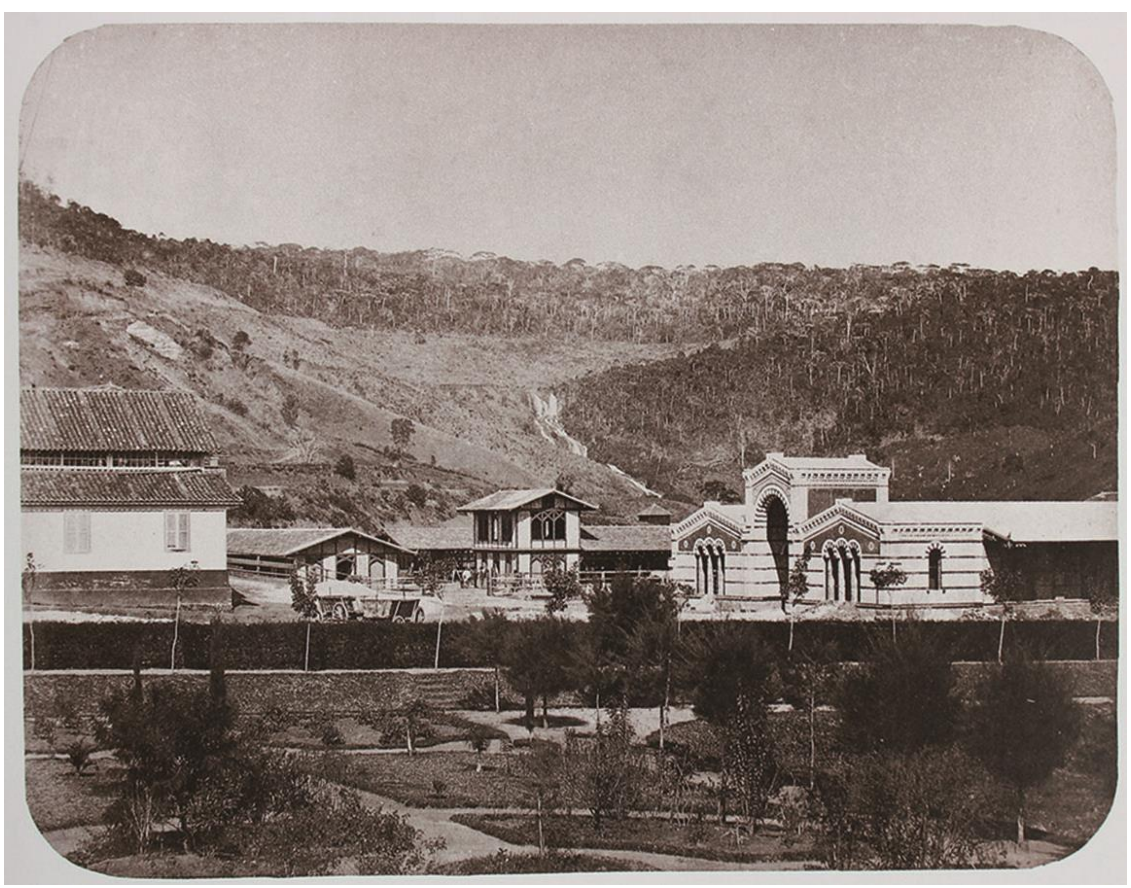

Figura 2. Estação do Juiz de Fora e oficinas da Companhia União e Indústria em 1861. Neste local foram treinados os operários que construíram a Estrada. Fonte: Revert Henry Klumb. Doze horas de diligência: guia do viajante de Petrópolis a Juiz de Fora, publicado em

1872.

Com a conclusão da estrada, muitos imigrantes da Cia. acabaram deixando a região. Os que permaneceram se dividiram nas funções de administração e manutenção da estrada, na vida como colonos ou trabalhando em diferentes oportunidades que surgiram em função do impulso econômico que a estrada propiciou. Um número significativo de imigrantes, homens livres ou escravos especializados, trabalharam na cidade em empreitadas públicas ou particulares, revelando um gradativo processo de especialização do trabalho. São (ou eram) dessa época, por exemplo, as seguintes obras envolvendo edificações em pedra e técnicas de cantaria na cidade de Juiz de Fora: a escadaria e o muro que existia na parte frontal da Paróquia de Santo Antônio, os pórticos laterais do Palacete Santa Mafalda, o edifício da antiga Cervejaria Augusto Kremer \& Cia, a Vila de Mariano Procópio e, posteriormente, a residência de Frederico Ferreira Laje.

Trabalhos especializados em cantaria também serão realizados em dezenas de propriedades rurais edificadas para o cultivo de café em toda a região, a exemplo dos encontrados nas fazendas Fortaleza de Santana em Goianá, Santa Sofia em Silveira Lobo, e Alpes em Mar de Espanha.

A Cia. União Indústria deixou como legado a especialização de novos trabalhadores no ramo da produção de tijolos, material que passou a ser utilizado com mais frequência em substituição às técnicas construtivas do período colonial. Em muitas situações, as edificações de tijolos foram articuladas com o uso de cantarias em alicerces, escadas, soleiras, colunas, pilares, arcos e cercaduras de portas e janelas. A utilização de pedras de cantaria em edificações de tijolos está presente em dezenas de edificações ainda preservadas na cidade de Juiz de Fora bem como por toda região.

\section{AS ESTRADAS DE FERRO}

Entre 1874 e 1875, a Zona da Mata Mineira esteve envolvida com uma grande obra que demandou canteiros habilidosos. Nesse período, constrói-se a 4ạ Seção da Estrada de Ferro D. Pedro II (Estrada de Ferro Central do Brasil a partir de 1889), com trecho de $78 \mathrm{~km}$ de extensão ligando o município de Juiz de Fora à cidade de Três Rios, RJ.

$\mathrm{Na}$ passagem pela região a estrada de ferro apresenta muitas edificações de pedra, se destacando encontros, pilares e arcos de pontes; túneis; muros de sustentação; plataformas; embasamentos de estações; cortes de pedra e bueiros. Um parte considerável dessas edificações estão em bom estado de conservação sendo ainda hoje utilizadas no transporte ferroviário. São notáveis os pilares e arcos de três pontes sobre o Rio Paraibuna, localizadas na divisa de Minas Gerais com o Rio de Janeiro, no distrito de Sobragi (Figura 3) e na cidade de Matias Barbosa. No bairro Retiro, em Juiz de Fora, ainda são visíveis os pilares de cantaria do Viaduto do Retiro, projetado pelo engenheiro Jorge Rademaker Grunewald em 1875. Com sua estrutura de ferro já totalmente removida, é considerado o primeiro viaduto ferroviário do Brasil totalmente projetado por um brasileiro (TELLES, 2011). 


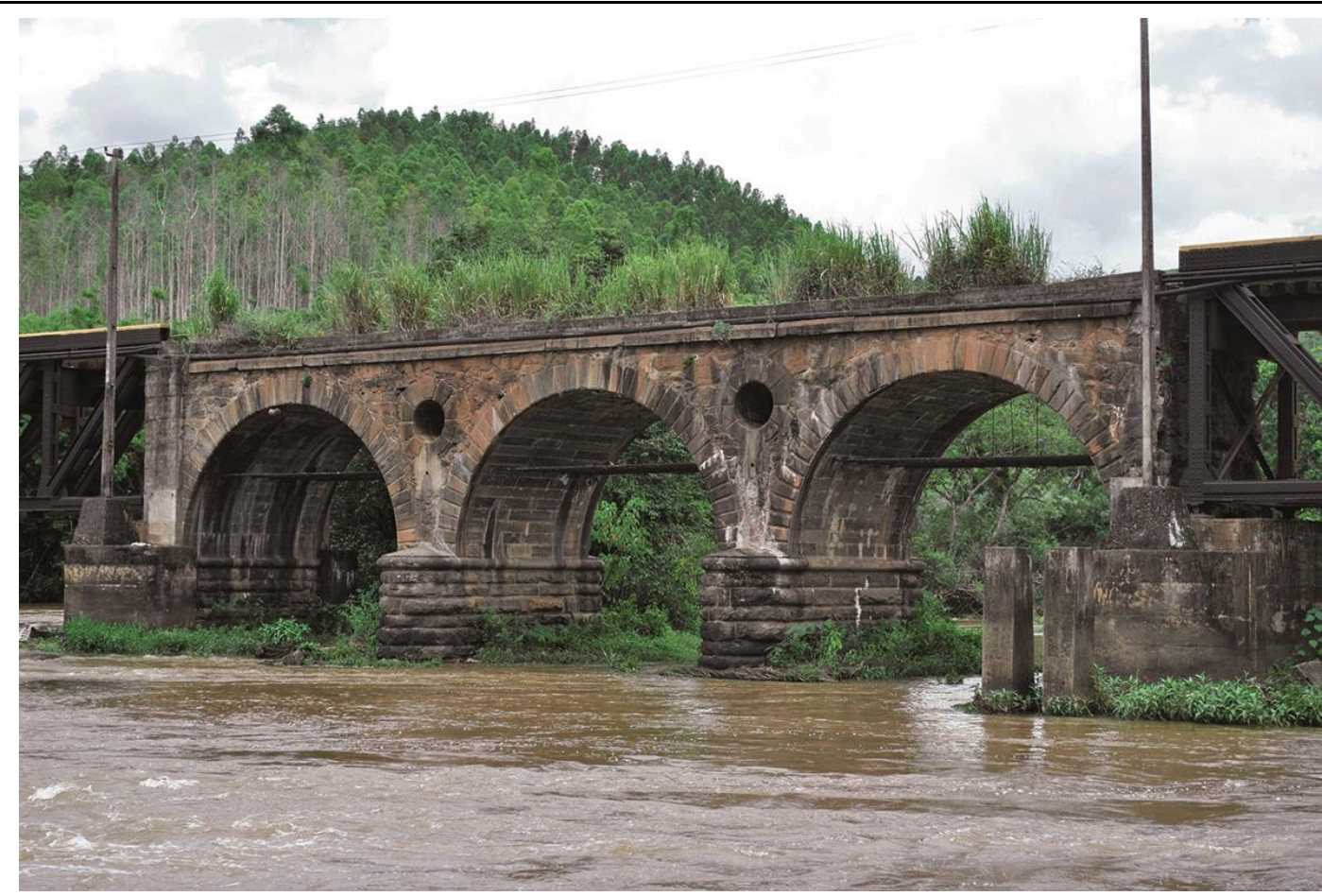

Figura 3. Ponte da E. F. Dom Pedro II, construída sobre o Rio Paraibuna em Sobragi, município de Belmiro Braga, MG, entre 1873 e 1874. Fonte: acervo fotográfico Ricardo De Cristofaro.

Em 1873 são iniciadas as obras da Companhia Estrada de Ferro Leopoldina por iniciativa de fazendeiros e comerciantes de café da Zona da Mata Mineira. O primeiro trecho dessa malha ferroviária foi realizado entre Porto Novo do Cunha no município de Além Paraíba e a cidade de Leopoldina.

A ferrovia conheceu crises financeiras que culminaram com a transferência do controle acionário para britânicos em 1898, quando passou a se chamar The Leopoldina Railway Company Ltd. A partir daí, novas linhas foram construídas e outras recuperadas no interior de Minas Gerais e Rio de Janeiro

Na década de 1950, a ferrovia foi encampada pelo Governo Federal, quando se transformou em Estrada de Ferro Leopoldina (EFL), sendo incluída na Rede Ferroviária Federal quando de sua criação (1957).

$\mathrm{Na}$ região, encontramos edificações com trabalhos em pedra e cantaria da Estrada de Ferro Leopoldina nos trechos que ligavam as cidades de Juiz de Fora a Ubá, e Rio Novo a Além Paraíba. Infelizmente, os ramais da Zona da Mata foram sendo desativados a partir da década de 1970, e a maior parte das estruturas da ferrovia encontra-se deteriorada e em estado de abandono.

\section{EDIFICAÇÕES E URBANISMO}

Nas últimas décadas do século XIX, trabalhos em pedra foram bastante utilizados na Zona da Mata e na cidade de Juiz de Fora em obras particulares e públicas. Eles estão presentes, por exemplo, em edifícios com soluções arquitetônicas diversificadas
- como neogótico, eclético e art nouveau - que seriam bastante utilizados também, em muitas cidades da região.

Nesse período a cidade de Juiz de Fora já contava com o trabalho de brasileiros que estudaram engenharia e arquitetura na Europa e Estados Unidos, assim como construtores, pedreiros comuns e empresários de pedreiras. Entretanto, em documentos da época, não é verificado o registro do ofício de canteiro, apesar de existirem despachos da Câmara Municipal de Juiz de Fora demandando especificamente "trabalhos de cantaria" para a realização de bancos de praça, lajeados para passeios, meios-fios, muros e escadarias. Acreditase, portanto, que o canteiro recebia a denominação de construtor ou pedreiro.

Nota-se também a chegada dos primeiros marmoristas na região executando entalhamentos para acabamentos arquitetônicos e sepulturas com mármore importado da Itália. No ramo de mármores atuavam luso-brasileiros e italianos, sendo possível verificar desde a década de 1870 , a presença de empresas como Pereira \& Costa. A partir de 1890 temos a Marmoraria Carrara e já no século XX Marmoraria São José/A Edificadora, Marmoraria Brasil e Marmoraria da Família Frateschi. A essas empresas se juntava o trabalho de marmoristas/escultores como Pedro Galli, Francisco Notaroberto, Giuseppe Bertochi, Lorenzo Fatica e Giuseppe Caporalli, entre outros. Já no início do século XX verificam-se bons trabalhos em mármore executados por Senatore, após anos 1920 Soranzo e 
Frateschi. Os Soranzo parecem ter sido os mais bemsucedidos e a família ainda está no ramo. Todos os outros após a morte dos italianos e dos primeiros descendentes faliram, encerraram o negócio ou não prosperaram diante das mudanças do mercado (SILVA, 2016).

Entre as grandes obras realizadas em cantaria na região, merece destaque a Igreja Matriz de São José das Três Ilhas, erigida entre 1878 e 1888 no município de Belmiro Braga. A igreja foi projetada por Quintiliano Nery Ribeiro, "talvez o primeiro engenheiro-arquiteto da terra", e executada sob coordenação do canteiro português Manoel Joaquim Rodrigues, sendo a maior edificação envolvendo trabalhos em pedra e cantaria em toda região da Zona da Mata Mineira (Figura 4).

Outro importante trabalho é o conjunto arquitetônico de edifícios, canais e barragens da primeira hidrelétrica construída e a entrar em operação na América do Sul, a Usina de Marmelos, construída pela Companhia Mineira de Eletricidade em diversas etapas entre 1889 e 1896. A companhia foi de extrema importância para a industrialização de Juiz de Fora, que, no final do século XIX, era a cidade mais rica e industrial de Minas Gerais.

\section{CONCLUSÃO}

Podemos perceber a importância da pedra em toda região desde os artefatos mais simples às construções mais sofisticadas e complexas. Esse material - por excelência rígido, resistente, além de abundante - foi, por muitos anos, uma das mais importantes alternativas para a realização de edificações e objetos.

Nota-se que o oficio da cantaria entrou em declínio na Zona da Mata Mineira no início do século $X X$, em grande parte devido a progressiva utilização do concreto armado. Entretanto, é interessante observar que, mesmo com as constantes transformações econômicas e sociais pelas quais passou a região, ainda é possível perscrutar uma época em que o trabalho com rochas era necessário e valorizado. Na malha urbana da cidade de Juiz de Fora, por exemplo, encontramos obras em pedra e cantarias por toda parte, por vezes desconhecidas, pouco valorizadas sendo registros notáveis da habilidade humana de superar limitações técnicas na busca por soluções práticas para os mais variados problemas.

Apesar de grande parte desses trabalhos em pedra ter sido descaracterizada por reformas, demolições e adaptações, eles representam uma parte importante do patrimônio artístico e arquitetônico local. São trabalhos repletos de importância histórica e de valores culturais, refletindo os caminhos da cidade e da região em seus diversos períodos de formação. Do mesmo modo, constituem "lugares de memória" que necessitam ser valorizados e preservados, nos quais é possível perceber habilidades e sabedorias depositadas em remotos ofícios.

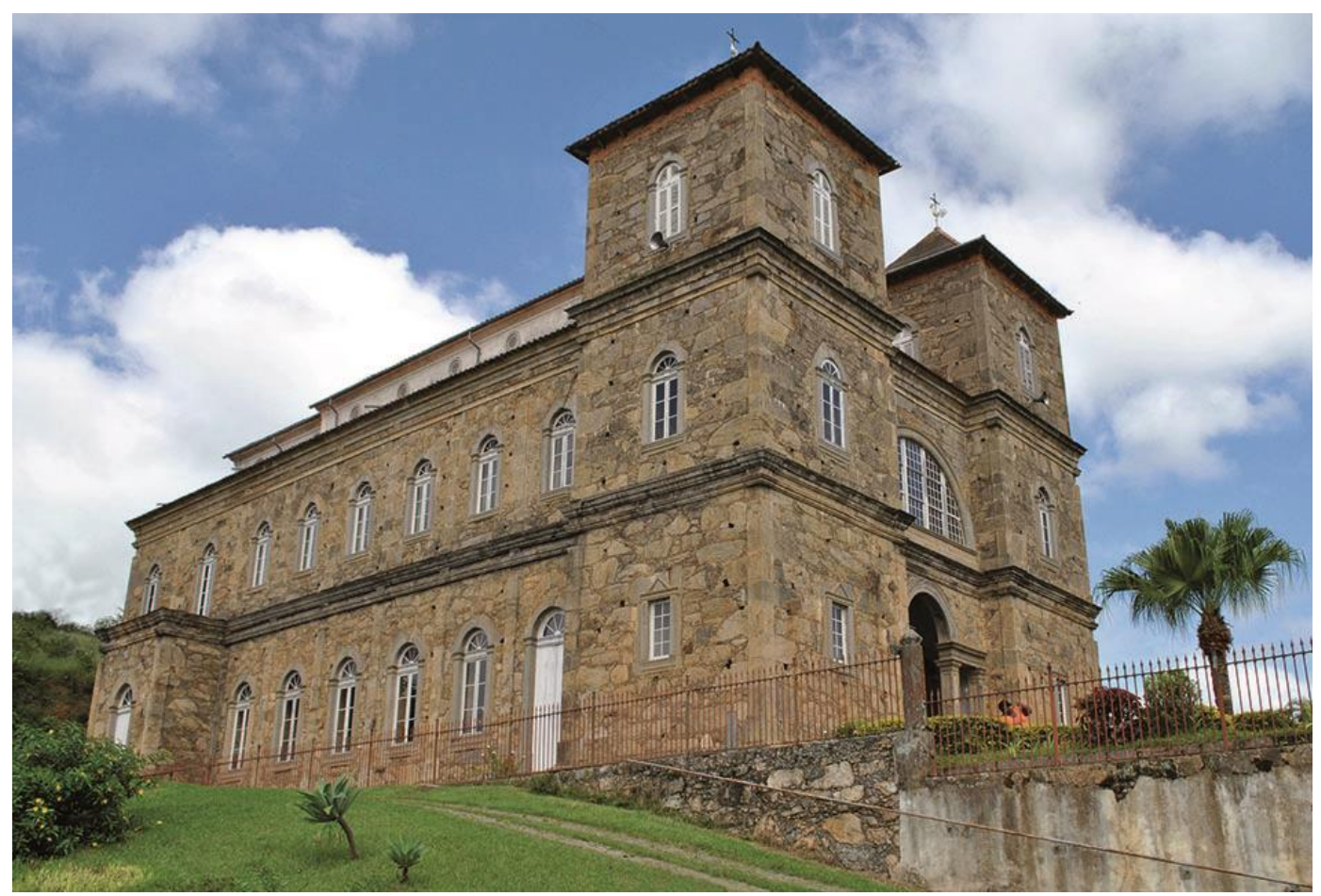

Figura 4. Igreja Matriz de São José do Rio Preto na Vila de São José das Três Ilhas, município de Belmiro Braga, MG. Fonte: acervo fotográfico Ricardo De Cristofaro. 


\section{REFERÊNCIAS BIBLIOGRÁFICAS}

BASTOS, Wilson de Lima. Caminho Novo Juiz de Fora. Juiz de Fora: Edições Paraibuna, 1993.

COSTA, Antônio, Gilberto. Rochas e Histórias do Patrimônio Cultural do Brasil e de Minas Gerais. Rio de Janeiro: Bem-Te$\mathrm{Vi}, 2009$.

ESTEVES, Albino; VIDAL, Oscar. Álbum do Município de Juiz de Fora. Juiz de Fora: FUNALFA Edições, 3ed., 2008.

GIROLETTI, Domingos. Industrialização de Juiz de Fora (1850 1930). Juiz de Fora: EDUFJF, 1988.

LAMOUNIER, Maria Lúcia. Entre a Escravidão e o Trabalho Livre. Escravos e Imigrantes nas Obras de Construção das Ferrovias no Brasil no Século XIX. Economia (Campinas), v. 9, p. 215245, 2010.

LESSA, Jair. Juiz de Fora e seus pioneiros. Juiz de Fora: UFJF, 1985.

PASSAGLIA, Luiz Alberto do Prado. Preservação do patrimônio histórico de Juiz de Fora. Edição Prefeitura de Juiz de Fora, 1982.

STHELING, Luiz José. Juiz de Fora. A Companhia União indústria e os alemães. Juiz de Fora: FUNALFA, 1979.
SILVA, Leandro Gracioso de Almeida. Memórias de um Ofício - Os marmoristas e o cemitério municipal de Juiz de Fora (18641974). Dissertação (Mestrado em Memória Social e Patrimônio Cultural) - Instituto de Ciências Humanas, Universidade Federal de Pelotas, Pelotas: 2016.

TELLES, Pedro Carlos da Silva. História da engenharia ferroviária no Brasil. Rio de Janeiro: NOTICIA \& CIA, 2011.

VASQUEZ, Pedro Karp. Álbum da Estrada União Indústria. Rio de Janeiro: Quadratium G, 1997.

Contribuição ao

1‥ Simpósio Brasileiro de Caracterização e Conservação da Pedra 14 a 16 de dezembro de 2016, Congonhas - MG

\section{Nota:}

É de responsabilidade da comissão editorial do Simpósio a revisão gramatical, ortográfica, de citações e referências bibliográficas. As normas de submissão podem se diferenciar das desta revista. 